\title{
LOCALIZACIÓN DE LAS CONSTRUCCIONES EN EL ÁMBITO RURAL ANTE LA PROTECCIÓN DEL PAISAJE
}

\author{
(LOCATION OF BUILDINGS IN THE RURAL AREA AND THE PROTECTION OF THE \\ COUNTRYSIDE)
}

Lorenzo García Moruno, Dr. Ingeniero Agrónomo

Julio Hernández Blanco, Ingeniero Agrónomo

Francisco Ayuga Téllez, Dr. Ingeniero Agrónomo

Justo García Navarro, Dr. Arquitecto

Fecha de recepción: $30-\mathrm{X}-98$

ESPAÑA

\begin{abstract}
RESUMEN
El presente artículo, constituye un estudio teórico apoyado en los sistemas de información geográfica, sobre la localización espacial de las construcciones. Ésta es una variable básica para el diseño y la consecución de una adecuada integración en el entorno. La influencia de este parámetro aparece como un factor fundamental capaz de afectar a la calidad del paisaje (García, 1998).
\end{abstract}

\section{SUMMARY}

This paper is a theoretic study, based on the GIS, about the spatial location of the constructions. This is a basic variable to design and achieve a suitable countryside integration. The influence of this parameter is a main factor that is able to modify the quality of the landscape (Garcia, 1998).

\section{Introducción}

La incorporación de las construcciones a un entorno natural, obliga a una planificación en la ejecución y a un estudio de criterios de diseño para conseguir una correcta integración en el paisaje. Es necesario, por tanto, un adecuado estudio que se anticipe a los problemas medioambientales y evite la incompatibilidad entre conservación y desarrollo.

La localización de la construcción es, junto con el color de las fachadas y la cubierta (Cañas, 1992), una variable fundamental que determina, en gran medida, la valoración de la integración en el entorno (García, 1998). Un conocimiento exhaustivo del mismo, permitiría al proyectista tener criterios para ubicar la construcción y diseñar según los objetivos perseguidos. La principal dificultad para su análisis radica, principalmente, en su carácter tridimensional que exige profundizar en el carácter compositivo de la escena. Algunos investigadores como Español (1995) han desagregado el elemento visual de la localización espacial en una serie de variables que facilitan el estudio: composición de la escena, fondo escénico y localización de las unidades. El análisis detallado de estos parámetros permite realizar un examen de la composición formada por la construcción y su entorno. En ella, el paisaje se comporta como un escenario en el que irrumpen actuaciones y donde la atención es el espectador con puntos de llamada y de indiferencia.

La posición que ocupa la construcción es decisiva en la lectura general del escenario. Por tanto, la ubicación 
elegida por el proyectista, no sólo debe estar acorde con la finalidad práctica del proyecto, sino que, al mismo tiempo, debe perseguir una visión armoniosa de la escena. Para que el profesional no sólo cuente con la ayuda de su intuición se van a exponer principios, más o menos generales, que pueden ayudar al proyectista a situar el edificio, determinar su visibilidad y la influencia en su integración en el paisaje. Todas estas reflexiones deben considerarse desde las distintas aproximaciones a la intervención, otorgando mayor relevancia a aquellas vías de comunicación con mayor tránsito, que se encuentren dentro de la cuenca visual, o a aquellos recorridos representativos del paraje o lugar.

Para la realización de este artículo se ha considerado al paisaje como el espacio que rodea al observador o, más concretamente, como el entorno visual desde el punto de observación. Según este principio se estudiarán el conjunto de la escena percibida y las relaciones entre sus elementos. De aquí se deduce que la individualización de sus elementos no puede considerarse como paisaje; un árbol o una ladera no son nunca paisaje, sino su composición conjunta. Además, la aplicación del término a una imagen reproducida (en este caso una fotografía) señala la ambivalencia del vocablo que cubre tanto una realidad tridimensional como una representación bidimensional de aquélla. Este proceso de sustitución posee un sólido mecanismo psicológico de asimilación de esquemas perceptuales, de tal forma que un observador puede percibir como distintos paisajes las diferentes vistas de una misma escena. En este mecanismo, el concepto compositivo toma una gran relevancia, pues la composición obtenida para cada vista es el resultado de la posición del observador en la escena y de su aproximación a la misma.

\section{El espacio como elemento visual}

El tamaño de una edificación, su orientación, ubicación, recubrimientos, etc., resultan ser elementos que la definen concretamente, dándole, a la vez, una opción de uso y valor. Es en el momento inicial del diseño cuando una opción técnica de proyecto se traduce en una opción estética y en una hipótesis de creación (Arnheim, 1962 y Lynch, 1992). El espacio, elemento visual de una escena, fue definido por Smardon (1979) como la disposición tridimensional de los objetos y las zonas del paisaje que conforman la composición escénica y que se configura mediante la relación entre sus componentes. De este parámetro visual se van a estudiar las tres características ya indicadas: composición escénica, fondo escénico y localización de las unidades.

Se parte de la base de que el valor del paisaje constituye un patrimonio tangible, considerándolo como la aplicación de la acción humana sobre un soporte natural. Este soporte es físicamente diferente en cada sitio, por la forma o volumetría del enclave, lo que origina unas condiciones de visión específicas en cada lugar. Además, la acción humana imprime al entorno un carácter que se hace visible a través de los elementos que se construyen sobre él.

En esta hipótesis de trabajo se reconoce al espacio, en un primer acercamiento, como una entidad volumétricamente definida por el relieve, condición previa sobre la que cualquier transformación actuará modificando su estructura (Seguí, 1996). La separación en la lectura de los componentes formales del sitio en dos grupos, de un lado los que se refieren al relieve y del otro los que están vinculados a la descripción morfológica de los elementos, permite estudiar la naturaleza cambiante/permanente del paisaje (Barba, 1996). Para ello, de un lado estará el relieve, como entorno o ámbito de partida en el que cualquier intervención modificará las características visuales y el orden general, que actuará como soporte de la intervención misma, a la que aportará recursos visuales, y del otro, la lectura morfológica de los elementos que configuran la escena, que permite un recorrido por ésta como escenario. Se identifica así la calidad esencial del paisaje como algo que es estructural en la forma, donde el relieve y la intervención poseen un carácter propio. El primero actúa como soporte del segundo, pero la lectura a través de la percepción visual, es conjunta; se convierte todo en un escenario o recinto global.

La actividad humana aplicada sobre el relieve inicial potencia trazos y geometrías, los contradice o introduce repetidamente un elemento para marcar un recorrido; éstas son maneras de apropiarse del genius loci o carácter del lugar y convertirlo en un territorio humano y, por tanto, intervenido. El estudio de estos conceptos de soporte y recinto, aporta argumentos esenciales para las teorías de intervención y es, por tanto, un fundamento importante para los criterios que intentan mantener la calidad de los paisajes.

En este trabajo se ha querido ilustrar el estudio teórico con imágenes obtenidas por una herramienta informática que permite profundizar en el análisis del espacio como elemento visual.Los Sistemas de Información Geográfica se presentan como un extraordinario apoyo, tanto para la representación digital del terreno como para su análisis tridimensional. Se han utilizado los programas ArcInfo y ArcView. Juntos permiten un detallado análisis de la información geográfica, su estudio por coberturas de información y su representación gráfica.

En esta representación tridimensional, tras crear el modelo digital del terreno, se ha realizado una retícula TIN (Triangulated Irregular Network). Basándonos en ella, y a modo de ejemplo, se ha realizado un estudio de visibilidad de una nave de planta rectangular con dimensiones $10 \times 20$ m en planta y de $8 \mathrm{~m}$ de altura máxima. Se ha situado dicha construcción en diferentes lugares y, en un caso, se 


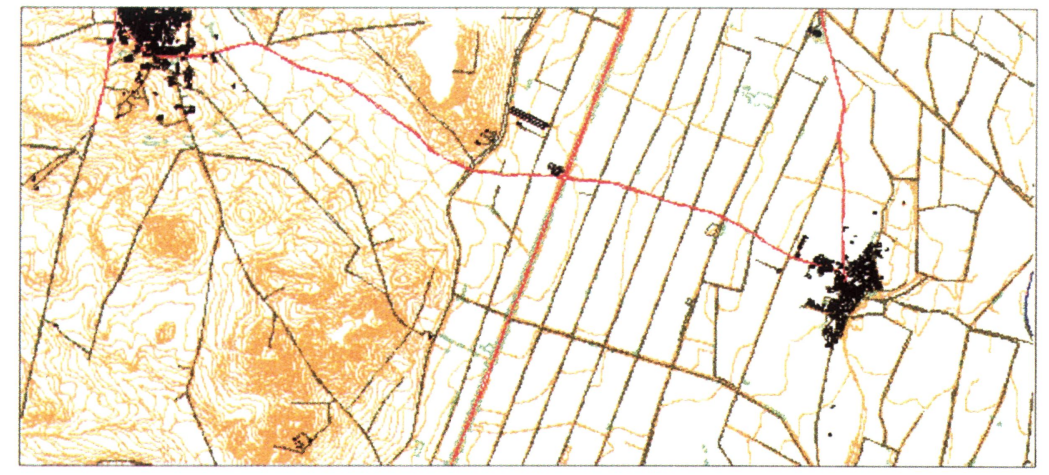

\begin{tabular}{|l} 
Leyenda \\
Rios y pozos \\
Edificaciones \\
Carreteras \\
Caminos rurales \\
Arbolado \\
Aguas superficiales \\
Curvas de nivel
\end{tabular}

Figura 1.- Cartografia de la zona de estudio.

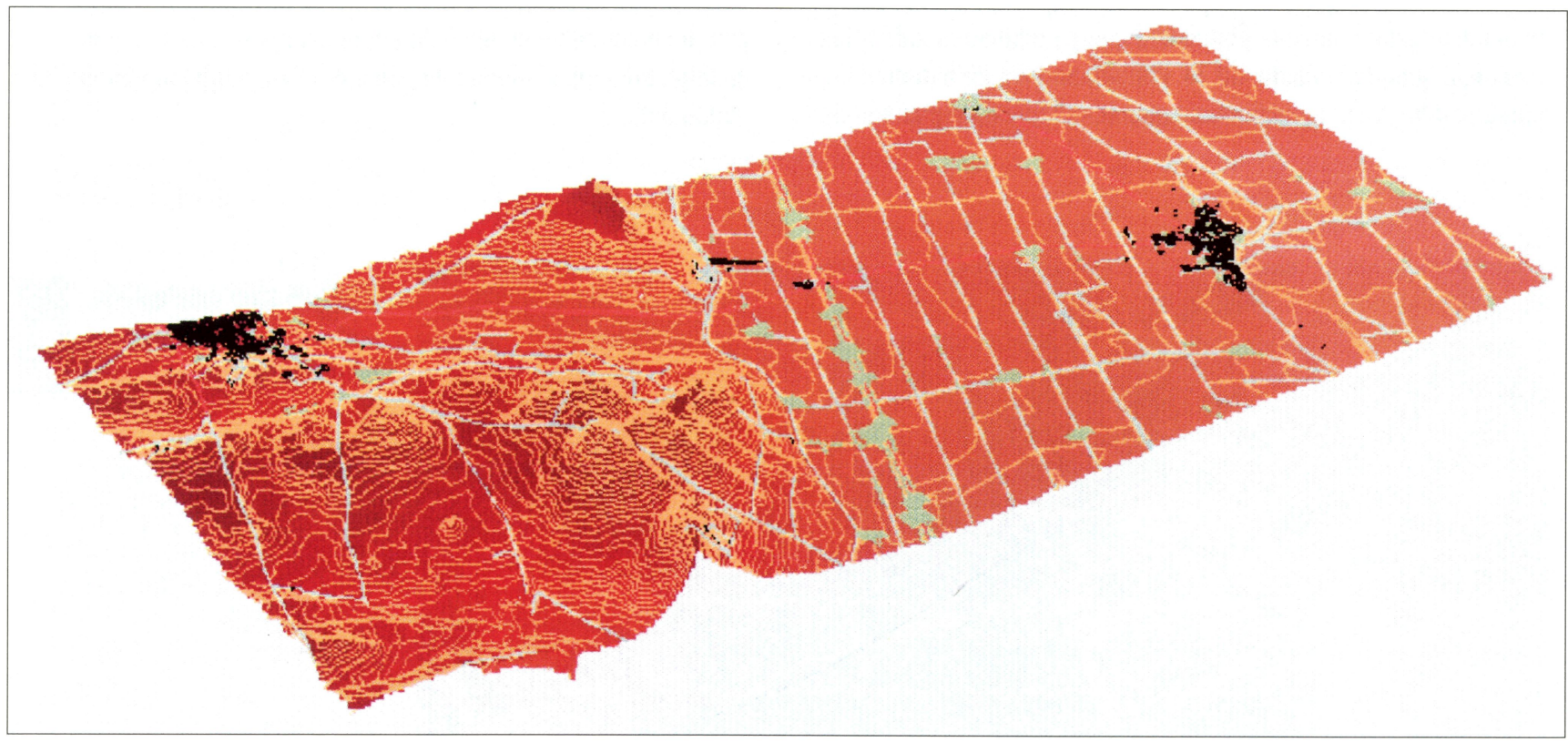

Figura 2.- Vista 3D del Modelo Digital del Terreno con superposición de coberturas lineales.

ha estudiado la influencia de la cobertura vegetal en la visibilidad de la edificación, especialmente el arbolado formado por álamos en los márgenes de carreteras, ríos y arroyos.

Los resultados alcanzados, algunos de los cuales se presentan en el artículo de forma gráfica, muestran la diferente distribución del área de visibilidad de la edificación según sea el punto donde se ha situado. Cada punto de localización espacial de la edificación se ha elegido en función de las distintas composiciones escénicas posibles en la percepción del paisaje.

Estos resultados no son sólo gráficos sino que forman una matriz de datos almacenada en el S.I.G. que nos permite su estudio y análisis estadístico, con el objeto de establecer relaciones entre el área de visibilidad y la composición escénica. Estas relaciones son la base para el análisis de la localización espacial de las edificaciones según la percepción visual de las mismas. De esta forma, se puede construir una herramienta que constituya una ayuda para planificadores y proyectistas a la hora de elegir localizaciones óptimas de construcciones agroindustriales para una mejor integración en el paisaje.

La zona elegida para este estudio está situada entre la provincia de León y la de Zamora, tiene una extensión de $12,6 \mathrm{~km}^{2}$ y comprende parte de los términos municipales de Matilla de Arzón, Cimanes de la Vega y San Cristóbal de Entreviñas. Se trata de una zona donde coexiste agricultura de secano y de regadío, y que tiene una gran potencialidad desde el punto de vista del turismo rural, estando esta actividad económica todavía poco desarrollada. 


\subsection{Composición escénica}

Normalmente, la visualización de una edificación surge tras un movimiento de aproximación a la misma. Una apertura gradual y paulatina de la visión siempre es más agradable a la percepción que un largo acercamiento monótono. Mientras permanece el interés por descubrir o informarse de algo la atención se mantiene activa (O’Farrell, 1987 y García, 1998).

Para estudiar y analizar este aspecto algunos autores definen índices que permiten leer la estructura visual del espacio sobre un plano topográfico. Por ejemplo, Higouchi (1983) establece seis índices para esta lectura: el efecto de la distancia, el ángulo de incidencia, profundidad e invisibilidad, ángulo de depresión, ángulo de elevación y profundidad de campo. Estos índices permiten estudiar las condiciones de lectura de la visibilidad en el interior de cada ámbito y las relaciones entre los diferentes puntos de vista y, además, justifican que la formación de la imagen visual se apoye en elementos que se interpretan objetivamente y que ayudan a conocer el impacto de cualquier intervención. El estudio de los datos topográficos nos aporta información sobre los índices de un punto de vista perteneciente a la cuenca.

Es decir, se pueden clasificar, para cada ámbito, unidades paisajísticas que respondan a espacios con cierta complejidad interior, de naturaleza bien distinta, y que resuman las condiciones de visibilidad interior y exterior que cada relieve propone. Además, se debe tener en cuenta que la percepción del proyecto se realizará mediante una aproximación al mismo, donde se podrán estudiar dos conceptos: uno será el proceso de muestra de información dentro del escenario y otro el de la exposición visual. El primero de ellos se aborda en la composición escénica y el segundo en el fondo escénico y la localización de las unidades.
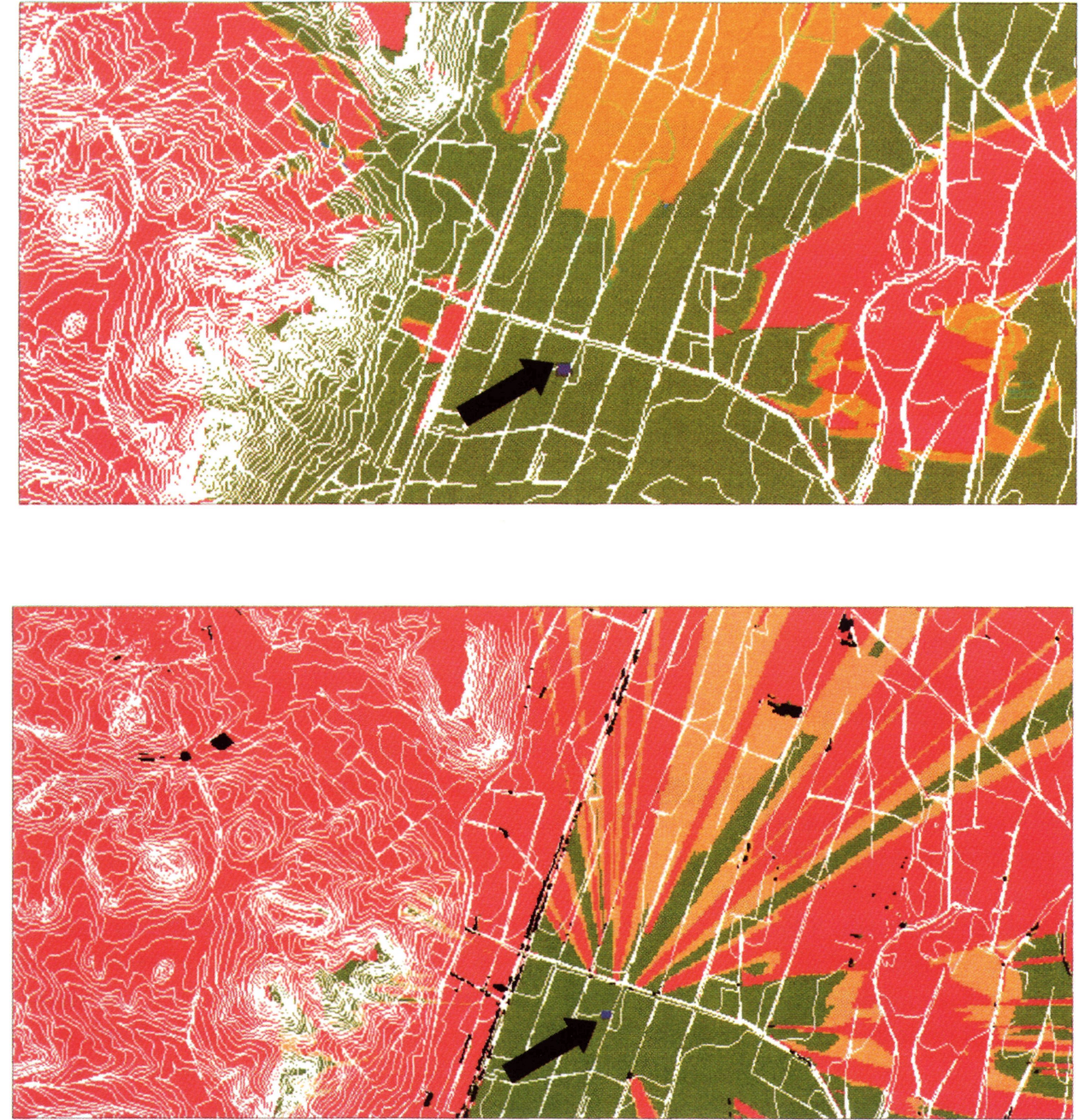

\section{Visibilidad completa Visibilidad parcial Visibilidad nula}

Visibilidad completa Visibilidad parcial Visibilidad nula Arbolado

Figuras 3 y 4.- Estudio en $2 D$ de las zonas desde las que se ve una edificación situada en una composición abierta, con y sin el efecto de filtro debido a la vegetación. 


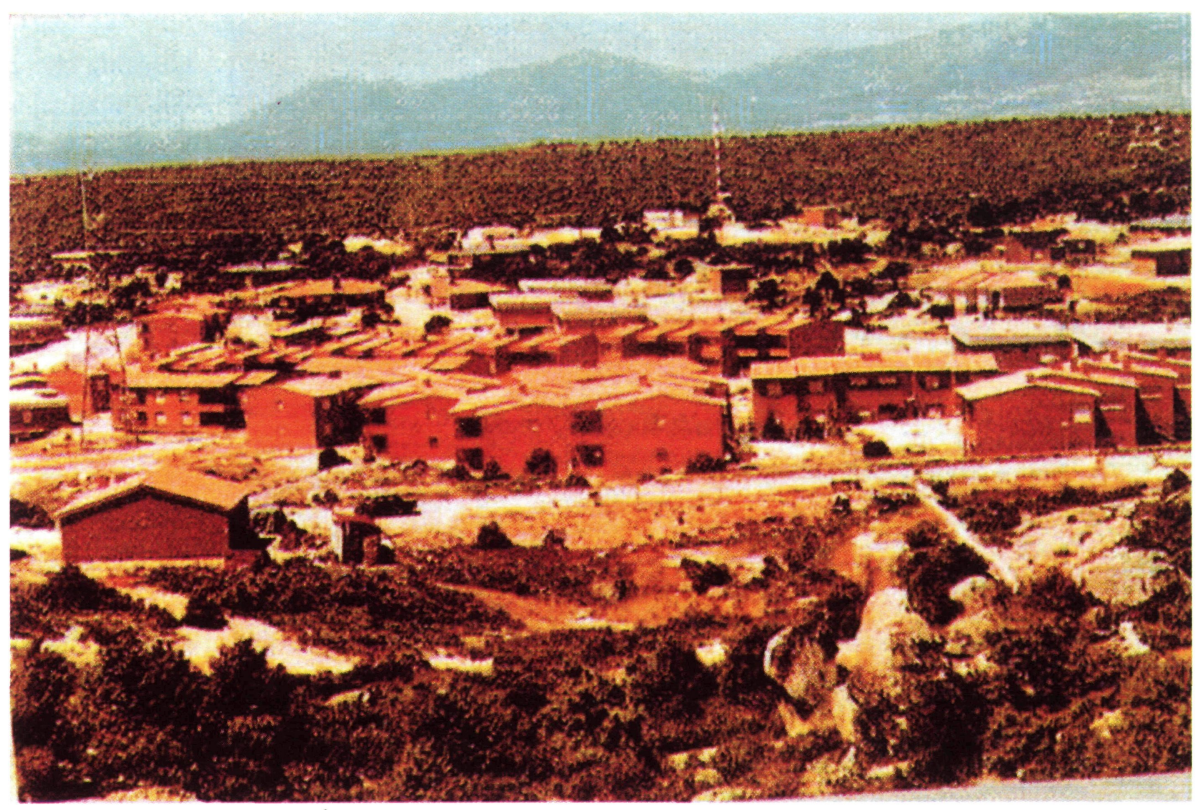

Figura 5.- Construcciones en composición escénica abierta.

Para cada escena se propone una definición en la que se resumen las propiedades que ofrece a la percepción. Es decir, el conjunto de atributos que influyen y conforman la capacidad de despertar la atención del observador. La calificación de cada escena se obtendrá siguiendo el siguiente esquema:

a) Existe ocultación parcial de la edificación. Se trata de una composición filtrada. Es una forma de dirigir la atención paulatinamente y que sea en el mismo movimiento de aproximación donde se descubre poco a poco la totalidad del edificio. Puede conseguirse con la presencia de una pantalla arbórea abierta que permita la visión a través de ella.

b) No existe ocultación parcial de la edificación.

b.1.) La construcción no se comporta como un punto de fuga de la escena.

b.1.1.) La construcción no es un elemento distintivo ni dominante en el paisaje.

b.1.1.1.) No existen límites aparentes para la visión, predominando los elementos horizontales y el cielo, dominando la escena. Se trata de una vista panorámica o abierta. En estos espacios no es posible referirse a un límite físico, ya que éste se encuentra en el horizonte. Los límites compositivos no están cerrados.

b.1.1.2.) Existen límites a la visión definidos por la presencia de barreras visuales que determinan una marcada definición del espacio. Se trata de una vista cerrada.
Cuando el elemento en estudio está conformando una composición de este tipo es percibido con rapidez; el espacio acotado despierta la atención del observador ante la limitada información.

b.1.2.) Si la construcción es un elemento distintivo y/o dominante en el paisaje se trata de una composición singular. Dominado por un elemento particular y diferenciado que protagoniza la escena. Suelen encontrarse en composiciones abiertas que conceden especial relevancia a la construcción.

b.2.) La construcción se comporta como un punto de fuga de la escena. Son composiciones focalizadas caracterizadas por la existencia de líneas paralelas u objetos alineados que constituyen el espacio focal que domina la escena. Así se puede conseguir que los distintos elementos escénicos confieran una posición relevante a la construcción.

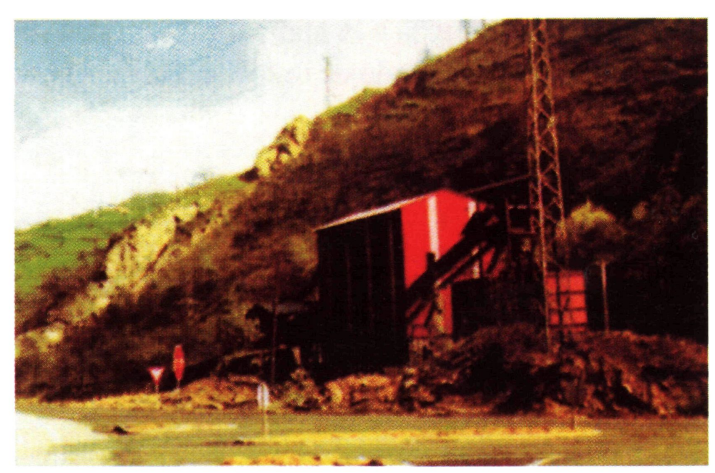

Figura 6.- Construcción en composición cerrada. 


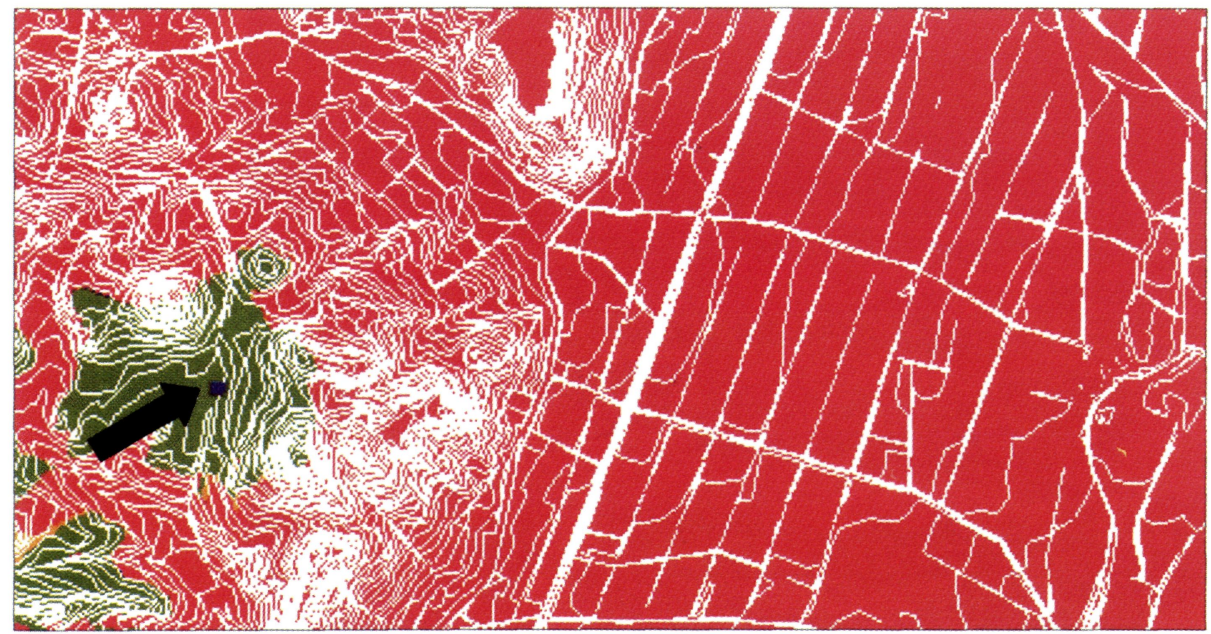

\section{Visibilidad completa Visibilidad parcial Visibilidad nula}

Figura 7.- Estudio en $2 D$ de las zonas desde las que se ve una edificación situada en una composición cerrada.

\subsection{Fondo escénico y localización de las unidades}

Estos parámetros visuales afectan a la situación topográfica relativa de elementos con identidad propia. Se definen con relación a la altitud y a las características de la composición. Su análisis es, por tanto, un estudio específico de la localización de la edificación, determinada, fundamentalmente, por su posición topográfica. Los objetos en localizaciones más visibles o estratégicas (centros focales) dominan sobre los demás. Para realizar el análisis de esta característica se va a estudiar, en primer lugar, el fondo escénico. Este fondo es la "cortina" que existe tras las vistas; puede ser el cielo, en composiciones abiertas; el agua, en escenas de márgenes litorales; o el propio terreno, en espacios cerrados. Tiene gran importancia ya que es determinante para la gama básica de contrastes; establece la nitidez de las líneas de siluetas y la continuidad y amplitud del espacio. Por tanto, este telón de fondo es relevante para determinar la llamada de la atención. Un objeto visto contra el cielo o el agua destaca más, por lo general, que cuando se ve contra el terreno, de ahí la importancia de la interrupción de la línea del horizonte (García, 1998). Tener de fondo el cielo o el agua, normalmente, por los diferentes tipos de colores y la ruptura de líneas como el horizonte o la ribera, hace que exista una fuerte llamada a la atención. El emplazamiento en un lugar como el fondo de un valle, donde es posible que se confundan los recubrimientos de las fachadas con los materiales del suelo, puede hacer también que se pierda el carácter de la edificación. Los valores que puede adoptar son:

Cielo: supone una interrupción de la línea del horizonte. El impacto visual de un edificio varía enormemente dependiendo de su posición en relación con la línea del horizonte. Cualquier edificio que rompa la línea del horizonte será visto desde muchos y diversos ángulos y también desde gran distancia. Es una forma de resaltar el edificio pero rompiendo una de las líneas más importantes que definen el paisaje.

Agua: se resalta el edificio con un efecto parecido al de la ruptura de la línea del horizonte y, además, se tapan vistas de uno de los elementos más importantes en la valoración estética de cualquier paisaje (Cañas, 1992).

Tierra: cuando se coloca como fondo escénico el propio terreno podemos tener diversas alternativas, dependiendo de la situación del edificio:

En fondo del valle: un edificio situado en un terreno llano en el fondo de un valle puede ser fácilmente absorbido por el paisaje, pudiendo llegar a perderse dentro del mismo.

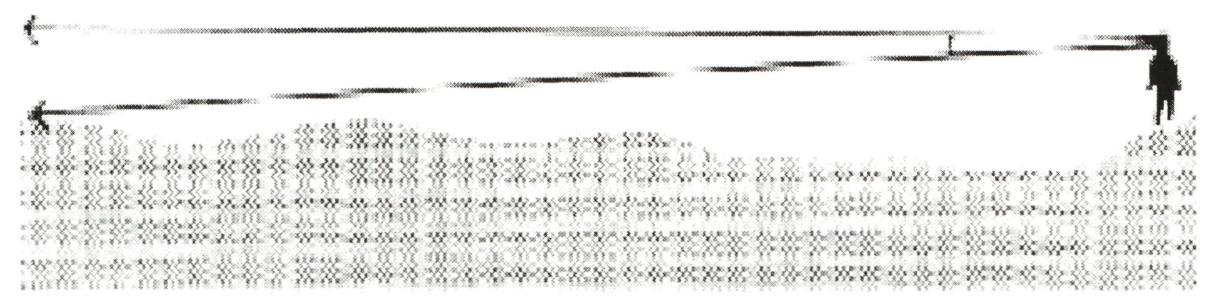

Figura 8.- Representación esquemática de una composición abierta. 


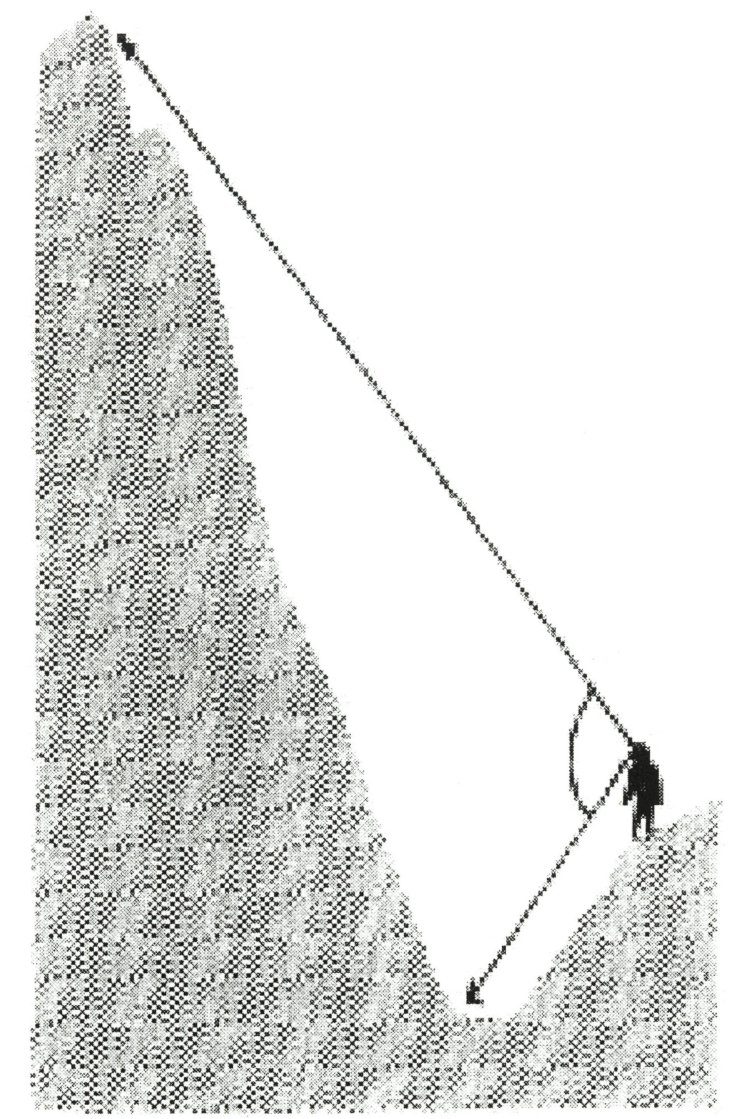

Figura 9.- Representación esquemática de una composición cerrada.

A media ladera: los edificios también pueden ser fácilmente acomodados a media altura de una elevación.

En el borde superior de la ladera: la situación es similar a la anterior, sólo que se hace más visible al edificio y con riesgos de interrumpir la línea del horizonte.

\section{Criterios de diseño}

Como pensamiento ilustrativo sobre la necesidad de controles objetivos y generales se citan unas palabras de Nan Fairbrother (citado por Tandy, C. 1979):

En Gran Bretaña la industria se ha ganado a pulso lo que los industriales denominarian una mala imagen..., y no ha de extrañarnos..., pues la hemos tratado como a un paria y no deja de ser natural que, por tanto, se haya comportado como tal. La industria ha desplegado una actitud de criminal descuido y suciedad, utilizando el paisaje público como cubo de basura de propiedad privada; edificios en ruinas y máquinas viejas, casuchas abandonadas, vallas cayéndose a trozos, latas y barriles abollados, viejas superficies de terrenos afirmados, pútridos vertederos de basuras y residuos industriales..., cosas todas ellas que simplemente se abandonan cuando ya no se las necesita y continúan ensuciando el paisaje durante generaciones y generaciones."

La primera decisión que ha de adoptar el constructor es la de determinar la localización comarcal, decisión previa y preparatoria para la búsqueda del solar concreto. En este momento es importante diferenciar dos conceptos: el impacto paisajístico, que implica cambios en el carácter o calidad del paisaje y el impacto visual, que está relacionado con los cambios que sufren las posibles vistas del paisaje y los efectos que estos cambios ejercen en las personas.

Aunque los dos están íntimamente relacionados, el impacto paisajístico y el visual no tienen que coincidir necesariamente (García, 1998). El impacto paisajístico puede ocurrir en ausencia de impactos visuales. Por ejemplo, en aquellos lugares donde las construcciones

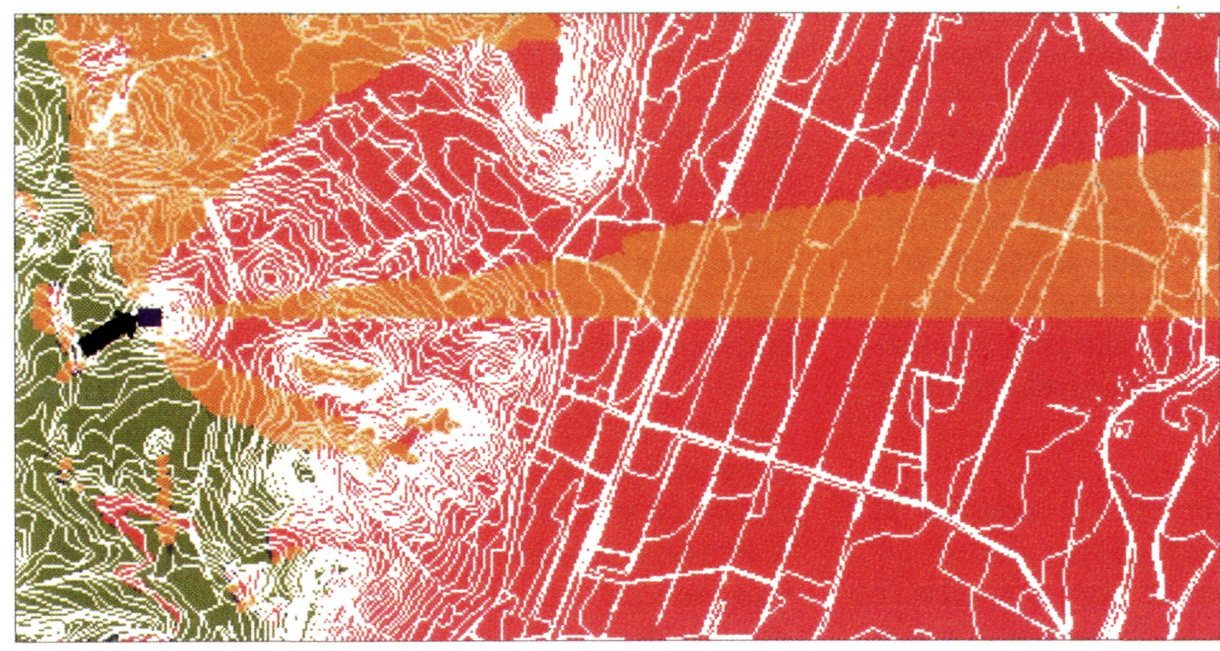

Visibilidad completa Visibilidad parcial Visibilidad nula

Figura 10.- Estudio en $2 D$ de las zonas desde las que se ve una edificación convertida, por su ubicación, en un elemento singular de la escena 


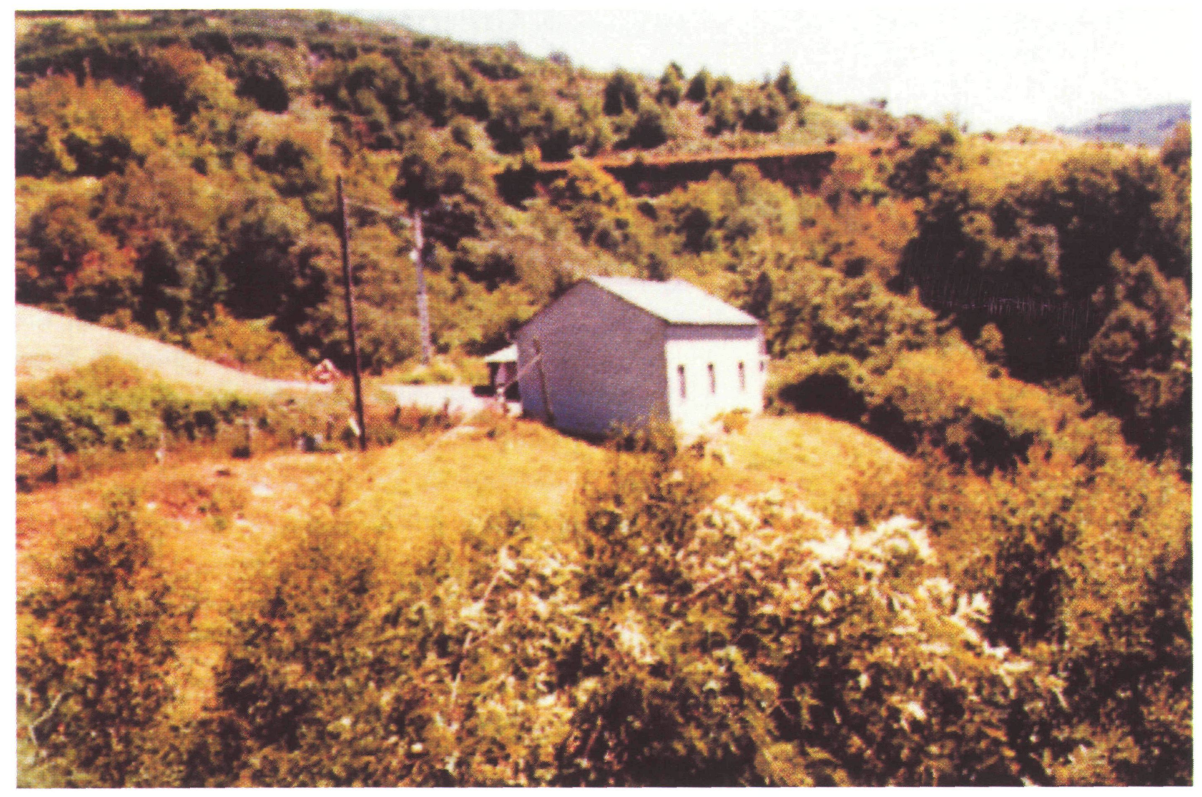

Figura 11.- Elemento singular en el paisaje.

que se identifiquen con el desarrollo económico estén completamente escondidas de las posibles vistas, la intervención antrópica habrá originado un cambio en el carácter del paisaje pero ocultada a las vistas. De forma similar, algunos desarrollos de infraestructuras, como la creación de nuevas comunicaciones situadas en un área industrial, pueden tener un significativo impacto visual, pero insignificante efecto sobre los rasgos definitorios del paisaje.

La integración de una edificación en el entorno es, por sí mismo, un tema difícil de abordar, pues origina un problema que se acrecienta cuando el nuevo edificio no se construye cerca de otros ya existentes. Aunque este hecho, cada vez es más complicado dada la gran proliferación de edificaciones en áreas rurales, implica un nuevo emplazamiento de la actuación humana, un terreno deja de estar virgen y existe, por tanto, un salto cualitativo que conlleva, además de un posible impacto visual, un muy probable impacto paisajístico. Por este motivo, la ubicación cerca de otras edificaciones suele evitar el riesgo de este tipo de impacto. En muchos casos, una nueva construcción puede suponer la introducción de un elemento singular en el paisaje y puede generar un considerable impacto visual. Lógicamente, si se sitúa detrás de algún promontorio o forma de relieve que la encubra, el objeto quedará oculto total o parcialmente, al menos desde algunos puntos de vista. Pero cuando el relieve es llano, resulta más difícil de ocultar.

Una vez seleccionado el solar, faltaría precisar el emplazamiento concreto de la edificación dentro del mismo. Es aquí donde realmente se pone a prueba la habilidad y capacidad del proyectista. Tiene que satisfacer las exigencias técnicas, así como los requerimientos de la dirección económica y comercial de la empresa, a la vez que ha de asegurarse una relación armoniosa entre las nuevas construcciones y el entorno. Por este motivo, debe sopesar las distintas alternativas y seleccionar la que considere más adecuada.

La vegetación desempeña muchas veces un inmejorable papel de enmascaramiento. Un elemento o alteración de grandes dimensiones puede resultar, en la mayoría de los casos, difícil de camuflar. Casi siempre es debido a su altura, demasiado elevada $\mathrm{y}$, por tanto, ni siquiera empleando una pantalla de árboles altos se podría conseguir un resultado satisfactorio. Para el proyectista, a veces, el encubrimiento puede ser un procedimiento de integración eficaz a emplear cuando se presenta algún elemento de grandes dimensiones y fuertemente discordante. Para estas ocasiones la disposición de la vegetación admite diversas alternativas, según el efecto que desee conseguirse. De tal forma que, tras analizar las distintas posibilidades que existen de instalar la pantalla de vegetación, se decidirá cuál es la situación más favorable para conseguir el efecto de apantallamiento perseguido. Una pantalla vegetal no es más que la disposición de árboles y arbustos formando una franja densa y de altura suficiente, de modo que no se pueda distinguir lo que hay al otro lado y sirva como barrera, no sólo visual, sino también protectora frente a determinados agentes atmosféricos.

Cuando un elemento que se pretende ocultar es excesivamente visible, se puede potenciar el efecto de ocultación levantando un caballón o montículo alargado de tierras en una zona próxima al lugar de observación, y situar sobre él una pantalla vegetal. En esta elevación artificial deben eliminarse las formas rígidas y artificiales; es decir, se deben conseguir perfiles suaves y 


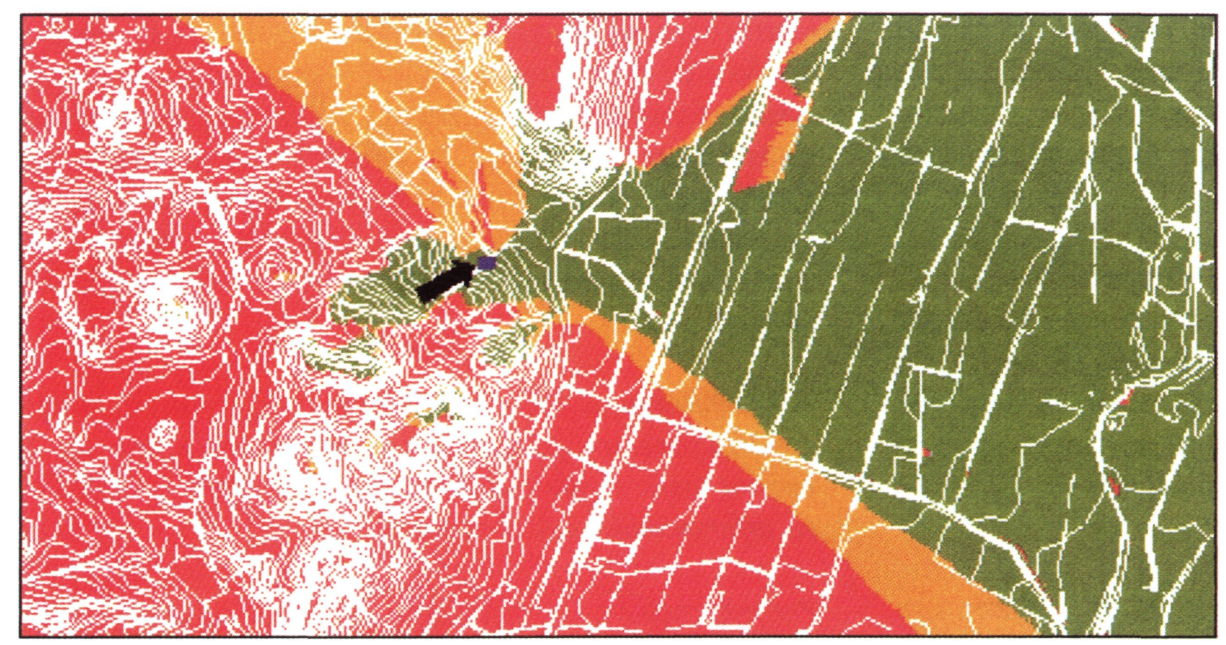

Visibilidad completa Visibilidad parcial Visibilidad nula

Figura 12.- Estudio en $2 D$ de las zonas desde las que se ve una edificación situada en un punto focal del terreno.

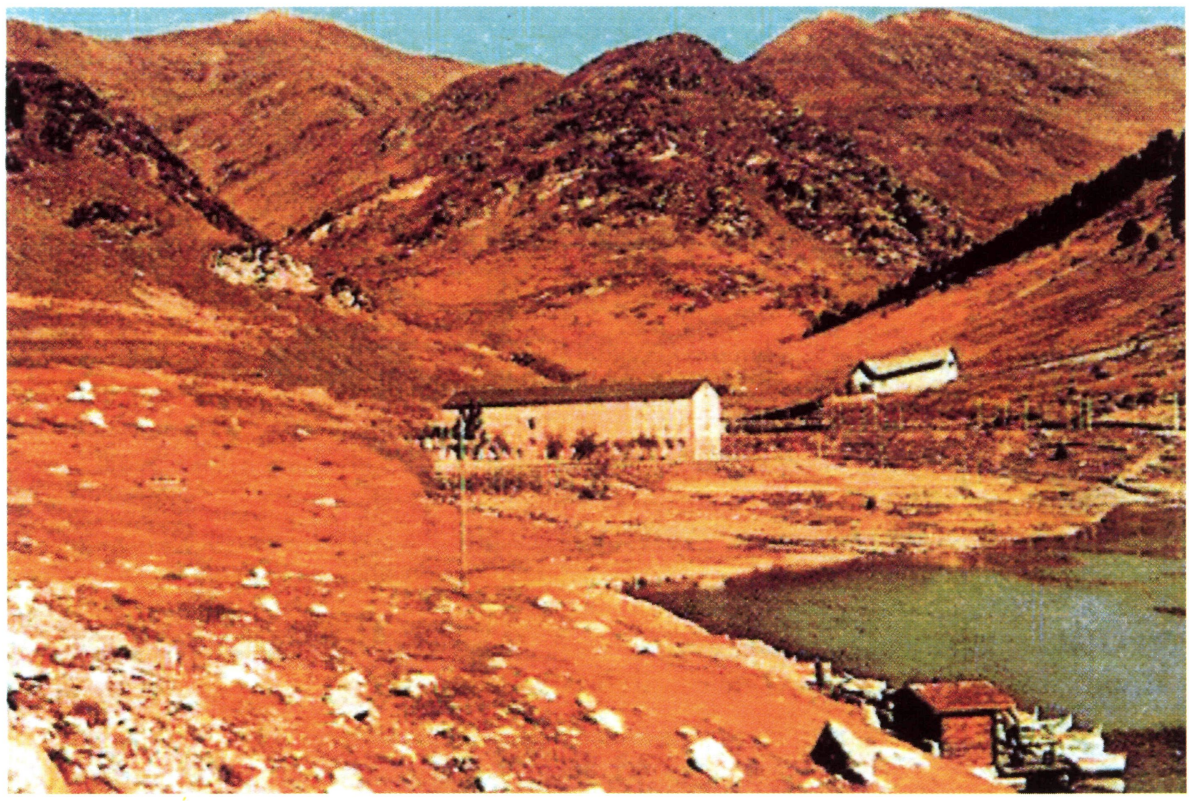

Figura 13.- Construcción focalizada en el paisaje.

redondeados y, posteriormente, realizar una siembra sobre todo el caballón. Para este cometido es conveniente emplear árboles de diferentes especies, algunos con hoja caduca o bien de hoja perenne que, además, presenten un porte adulto suficiente como para realizar con garantías su papel de ocultación. Además, es interesante escoger especies con longevidad y velocidad de crecimiento diferentes. Los ejemplares de crecimiento más rápido comenzarán a ejercer su apantallamiento en un corto período de tiempo, y cuando sean adultos irán siendo sustituidos por especies más longevas. Deben plantarse intercaladamente arbustos densos, que oculten también la zona inferior, por debajo de la copa de los árboles. Asimismo, se debe evitar alinear las plantas utilizadas, colocándolas de modo alternado o al azar, dentro de una franja.
Pero el encubrimiento no tiene por qué ser el método óptimo ni el más eficaz. Se pueden estudiar otras alternativas desde el punto de vista espacial. Normalmente, se deben perseguir emplazamientos que permitan al edificio ser visible, no pasar desapercibido, pero sin focalizar excesivamente la atención. Es decir, al camuflar u ocultar un edificio, éste se adapta a los tipos del entorno, perdiendo su propio carácter o, sencillamente, no aportando ningún tipo nuevo; la construcción huye de la diferenciación. Si se consigue un diseño carente de ambigüedades, donde la intervención antrópica mantenga su propio carácter, ofrezca una diferenciación compositiva y, al mismo tiempo, intente formar parte de una unidad paisajística, también ésa puede ser una solución eficaz, desde el punto de vista del impacto visual. Es necesario estudiar la lectura y composición de la escena tenien- 
do en cuenta la nueva incorporación. Una muestra parcial y paulatina de la construcción nos habla de una comunicación filtrada, donde la exposición es gradual y pausada, aumentando la ocupación de la escena a medida que el observador se aproxima.

La composición de la escena es la primera característica que condiciona la lectura del panorama y puede resaltar o mitigar la atención de una zona concreta. De hecho, los edificios grandes en espacios cerrados suelen despertar más la atención que en espacios abiertos, su ocupación de la escena suele ser mayor y, además, rompen con más facilidad el cono de la visión.

Cuando las edificaciones que emergen en el terreno se comportan como puntos singulares, despiertan la atención con profusión y, por tanto, su visibilidad, desde el primer contacto con la escena, es muy alta. Algo muy similar ocurre cuando todas las fuerzas del terreno conducen a la visión a un determinado lugar. Se habla entonces de una visión focalizada. Obviamente, las construcciones en estos lugares gozan de un privilegio grande para su visualización $y$, por tanto, su diseño debe ser cuidado en extremo (Tabla I). Esta tabla es una síntesis que puede ayudar a relacionar la ubicación de nuestra edificación con su percepción.

Normalmente, se debería tender a que "la construcción no constituyese un punto dominante de atención en la escena, pero si que fuese claramente visible y estuviese diferenciada del entorno".

Por este motivo, se recomienda que una localización en el espacio no disponga sólo de características que la hagan muy visible, ni tampoco sólo de aquéllas que la oculten. Un término medio puede ser lo ideal.

TABLA I

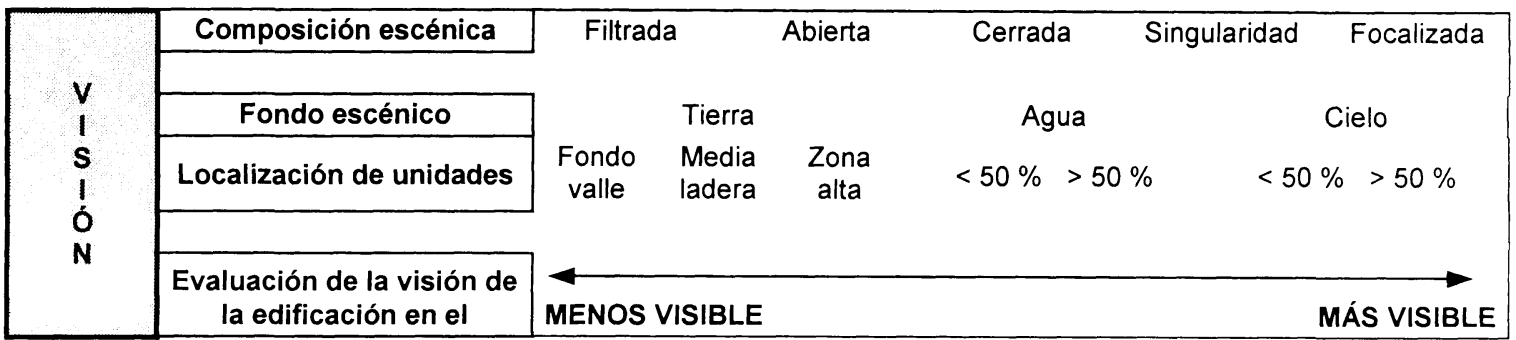

\section{BIBLIOGRAFÍA}

- AGUILÓ, M. y COL.: (1992); "Guía para la elaboración de estudios del medio físico". Ministerio de Obras Públicas y Transportes. Madrid.

- ARNHEIM, R.: (1962); “Arte y percepción visual”. Editorial Universitaria de Buenos Aires. Buenos Aires.

- BARBA, R.: (1996); "El impacto ambiental en el planeamiento urbanístico". Fundación Cultural COAM, Área de Urbanismo. Madrid.

- CAÑAS, I.: (1992); "Integración de las construcciones agrarias en el paisaje: el color”. Tesis doctoral, sin publicar. UPM, Madrid.

- ESPAÑOL, I.: (1995); "Paisaje, conceptos básicos”. E.T.S.I. Caminos, Canales y Puertos. Madrid.

- GARCÍA, L.: (1998); “Criterios de diseño para la integración de las construcciones rurales en el paisaje”. Tesis doctoral. Sin publicar. UPM, Madrid.
- HIGOUCHI, T.: (1983); "The visual and spatial structure of landscapes". The M.I.T. Press, Cambridge Mass,

- LYNCH, K.: (1992); "La administración del paisaje". Norma Editorial.

- O'FARRELL: (1987); "Farm buildings and the environment". Ed. An Foras Taluntais. Dublin.

- SEGUÍ, J.: (1996); “El paisaje proyectado o la fuerza del lugar". Revista Geometría, $n^{\circ}$ 21, pp. 3-16. Madrid.

- SMARDON, R.C.: (1979); "The Interface of Legal and Esthetic Considerations". Proceedings of Our National Landscape. April 23-25. Incline Village, Nevada. USDA For. Ser.,PSFRES. Berkeley, California.

- TANDY, C.: (1979); “Industria y paisaje". Ed. Leonard Hill Books. Instituto de Estudios de Administración Local. Madrid. 